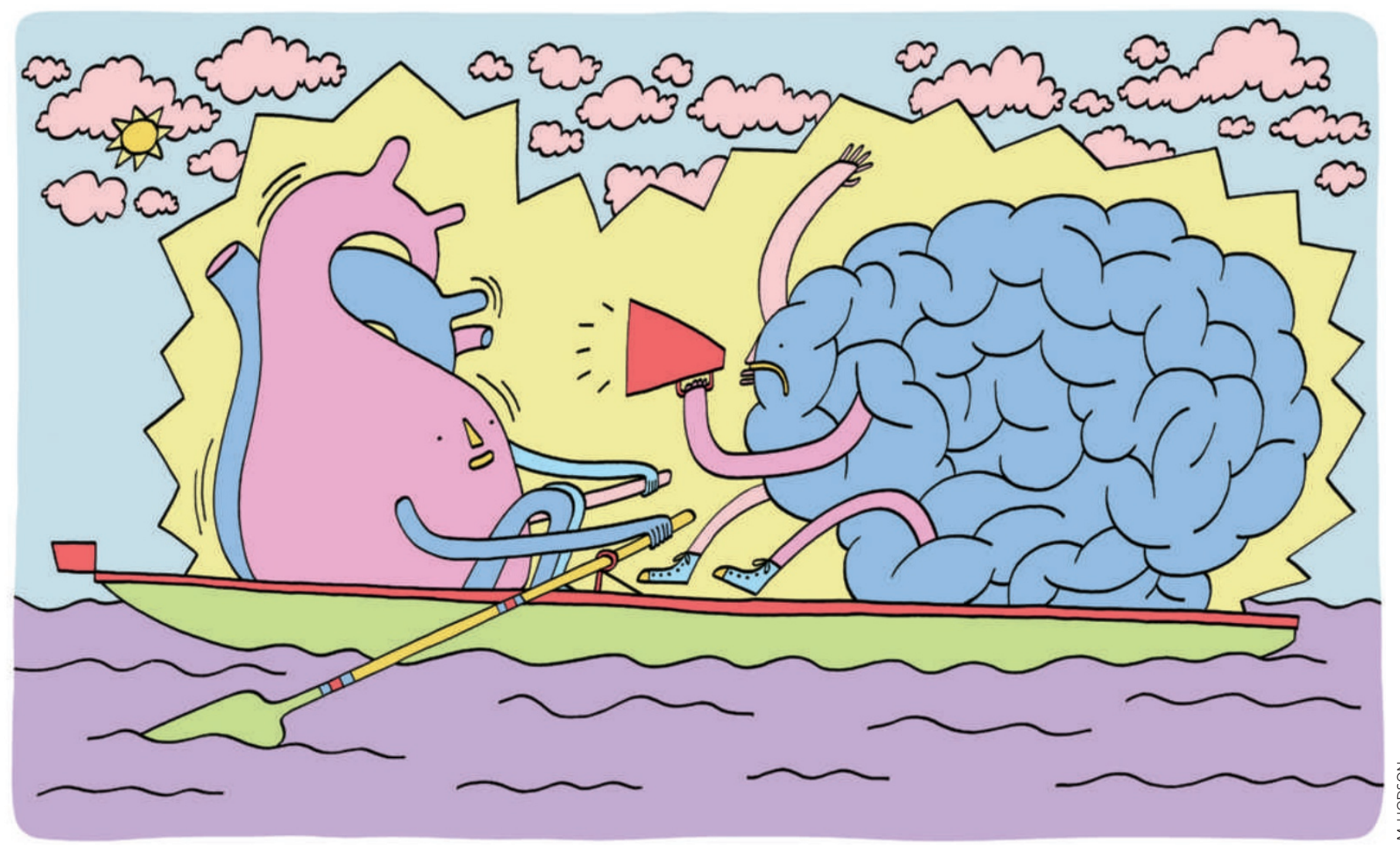

\title{
Why do intelligent people live longer?
}

\section{We must discover why cognitive differences are related to morbidity and mortality, argues lan Deary, in order to help tackle health inequalities.}

Ten years ago, on 16 October 1998, I presented findings that people from Aberdeen with higher childhood IQs - measured at age 11 in the Scottish Mental Survey of 1932 - were significantly more likely to survive to age 76 . It was at a psychology seminar at Glasgow Caledonian University, UK. For one audience member, the finding did not go down well. "So, you're saying that the thick die quick?" It was not a point of clarification; it was an accusation. The temperature in the room rose as the questioner railed against a result he found insulting and wanted to invalidate. Hadn't intelligence tests been discredited?

Actually, no. Scores from cognitive-ability tests (also known as intelligence tests or IQ tests) have validity that is almost unequalled in psychology ${ }^{1}$. A general cognitive-ability factor emerges from measures of diverse mental tasks, something that hundreds of data sets since 1904 have replicated. People's rankings on intelligence tests show high stability across almost the whole lifespan, are substantially heritable and are associated with important life outcomes - including educational achievements, occupational success and morbidity and mortality. More thumping confirmatory studies of the link between intelligence and mortality have appeared since our first work. One of these contains nearly a million Swedish men tested at around age 19 during military induction and followed for almost 20 years ${ }^{2}$. It shows a clear association: as intelligence test scores go up the scale, so too does the likelihood of survival over those two decades.

When we attempted to publish our original study, we came across a different complaint: the journals to which we submitted our initial findings said they found the link obvious. It was already well known that health inequalities are associated with different social backgrounds. That was deemed the likely explanation for the finding. But it has since been shown that childhood social class does not account for the association between childhood intelligence and later mortality ${ }^{3}$.

Intelligence can predict mortality more strongly than body mass index, total cholesterol, blood pressure or blood glucose, and at a similar level to smoking ${ }^{4}$. But the reasons for this are still mysterious. That needs to change. Reducing health inequalities is a priority, and to do that we need to determine their causes.

\section{Catchy headlines}

We weren't the first to find a link between individually assessed intelligence and mortality. In 1992 a report in the journal Personality and Individual Differences showed that mental test scores of Australian soldiers at the time of induction for the Vietnam War were associated with deaths up to early middle age ${ }^{5}$. The finding should have been headline grabbing, but it has been slow to gain a popular and academic reaction. It wasn't until our 2001 paper in the British Medical Journal ${ }^{6}$ that the media began to pay attention - 'Brainy Kids Live Longer' proclaimed Scotland's Daily Record; 'The Higher Your IQ, the Longer You're Likely to Live' said Britain's Daily Mail. And the papers became more frequently cited.

Cognitive epidemiology has since become 
established as a distinct area of study, and a systematic review has established the association between early-life intelligence and mortality across different populations, in different countries, and in different epochs ${ }^{3}$.

\section{Four explanations}

The field has focused on four non-exclusive possibilities for the link between intelligence and death. First, what occurs to many people as an obvious pathway of explanation, is that intelligence is associated with more education, and thereafter with more professional occupations that might place the person in healthier environments. Statistical adjustment for education and adult social class can make the association between early-life intelligence and mortality lessen or disappear ${ }^{2,7}$. But not always.

Moreover, cause and effect among intelligence, education and social class is not settled. It may be that a person with more and better education achieves a higher IQ score; but a child with a high IQ score is more likely to undergo more years of education, attain higher qualifications and go on to a better job. Thus, adjusting for education and social class in the intelligencemortality association could be an over-adjustment - it
"Why do we die when we do, and to what extent is this question tractable?" lower likelihood of dying in 15 years of further follow-up. Adjusting for metabolic syndrome reduced the association of intelligence with total mortality by up to $10 \%$, and with cardiovascular disease mortality by up to $32 \%$.

Third, mental test scores from early life might act as a record of insults to the brain that have occurred before that date. These insults - perinatal events, or the result of illnesses, accidents or deprivations before the mental testing might be the fundamental cause behind both intelligence test scores and mortality risk. So far, little evidence supports this. Both birth weight (commonly used as a marker of fetal development) and parental social class (used as a marker of early-life circumstances) are correlated with intelligence test scores. But, when the associations between intelligence and mortality are adjusted for these factors, the association remains almost unaltered. Perhaps subsequent work may find better indicators of early-life tribulations that have more explanatory power.

Fourth, mental test scores obtained in youth might be an indicator of a well-put-together system. It is hypothesized that a well-wired body is more able to respond effectively to environmental insults. This 'system integrity' idea has a parallel in the might weed out some of the very influence of intelligence that we are trying to detect. Linda Gottfredson, in the School of Education at the University of Delaware in Newark, has proposed that intelligence is a 'fundamental cause' of the association between education, social class and health ${ }^{8}$. Her gauntlet-throwing-down paper - which has just won the prestigious George A. Miller award from the American Psychological Association - is provocative to epidemiologists, who tend to look outside rather than within the individual for causes of health inequalities. Those with contrasting ideas in this area need a chance to debate their theories and work towards a solution.

Second, people with higher intelligence might engage in more healthy behaviours. Evidence is accruing that people with higher intelligence in early life are more likely to have better diets, take more exercise, avoid accidents, give up smoking, engage in less binge drinking and put on less weight in adulthood.

But this too doesn't seem to be the whole story. In an assessment known as the US Vietnam Experience Study ${ }^{9}$, higher intelligence test scores at induction were associated with a lower likelihood of developing metabolic syndrome in middle age - a condition combining factors such as obesity, high blood pressure and impaired glucose metabolism. In the same study, higher intelligence was also associated with field of ageing, where some data suggest that bodily and cognitive functions age in concert.

Some supporting evidence comes from the finding that simple reaction speed - the time taken to press a button when a stimulus appears - can displace intelligence test scores as an even better predictor of mortality risk ${ }^{10}$. Reaction-time tasks do not require complex reasoning, and so are unlikely to be improved by education. A major job for the field is to discover better markers for system integrity and to test their explanatory power for mortality.

\section{Unclear chain}

Although intelligence plays a part in health behaviours and health outcomes that contribute to specific causes of death, a clear chain of causation from intelligence to health outcomes and then to death has not emerged. Different types of mortality, including cardiovascular disease, homicide and suicide, seem to demand their own explanations for being associated with early-life intelligence. Those who found the intelligence-death association 'obvious' must think again.

The new University of Edinburgh Centre for Cognitive Ageing and Cognitive Epidemiology, of which I am director, opened on 1 September 2008. High among its aims is to provide a forum and infrastructure to unpick the extent to which cognitive and other effects underlie different causes of mortality. Psychologists, epidemiologists, neuroscientists, behavioural geneticists, statisticians and others will interact in our programme, providing complementary skills to understand the causal pathways.

The field has benefited from many varied data sets, none of which was initiated with the aim of asking why intelligence foretells death. Considerable credit for identifying such data goes to David Batty, an epidemiologist interested in the causes of chronic disease and a colleague of mine since 2002, who was responsible for establishing links with the Swedish conscripts study and the Vietnam Experience Study, amongst others, to test our theories.

High among our priorities is to find more such relevant data sets, especially some involving twins. Members of our centre are now analysing twin studies from Minnesota and Denmark that seem, in the early stages, likely to be informative about the intelligence-mortality link.

There is also a search for other, non-cognitive psychological characteristics that are associated with living longer. For example, it seems that, independently of any association with intelligence, being more dependable or conscientious in childhood is also significantly protective to health. Children who scored in the top 50\% of the population for intelligence and dependability were in one study ${ }^{11}$ more than twice as likely to survive to their late sixties as children scoring in the bottom half for both.

Why do we die when we do, and to what extent is this question tractable? This fundamental curiosity drives our team and others on to better scientific studies. More than satisfying our curiosity, the search has practical implications. The influence of intelligence on mortality isn't fated; intelligence does not unalterably spin, measure and cut the thread of life. The things that people with higher intelligence have and do that make them live longer may be found and, we hope, shared, towards the goal of better and more equal health.

Ian Deary is director of the University of Edinburgh Centre for Cognitive Ageing and Cognitive Epidemiology, Edinburgh EH8 9JZ, UK. e-mail: i.deary@ed.ac.uk

1. Deary, I. J. Intelligence: A Very Short Introduction (Oxford Univ. Press, 2001)

2. Batty, G. D. et al. Epidemiology (in the press)

3. Batty, G. D., Deary, I. J. \& Gottfredson, L. S. Ann. Epidemiol. 17, 278-288 (2007).

4. Batty, G. D. Shipley, M. J., Gale, C. R., Mortensen, L. \& Deary, I. Heart doi:10.1136/hrt.2008.149567 (2008).

5. O'Toole, B. I. \& Stankov, L. Pers. Individ. Dif. 13, 699-716 (1992).

6. Whalley, L. J. \& Deary, I. J. Br. Med. J. 322, 819-822 (2001)

7. Hart, C. et al. Psychosom. Med. 65, 877-883 (2003).

8. Gottfredson, L. S. J. Pers. Soc. Psychol. 86, 174-199 (2004).

9. Batty, G. D. et al. Diabetologia 51, 436-443 (2008).

10. Deary, I. J. \& Der, G. Psychol. Sci. 16, 64-69 (2005).

11. Deary, I. J., Batty, G. D., Pattie, A. \& Gale, C. R. Psychol. Sci. 19, 874-880 (2008). 